\title{
The Effect of Longterm Growth Hormone Treatment in Children with Short Stature Secondary to Intrauterine Growth Retardation
}

\author{
J. L. Chaussain, P. Chatelain and J. C. Carel \\ Hôpital St Vincent de Paul, Paris (JLC, PC), Hôpital Debrousse, Lyon (JCC), France
}

Key words: intrauterine growth retardation, short stature, GH therapy

The great majority of children born with intrauterine growth retardation (IUGR) has spontaneous catch up growth during the first 2 years of life. This proportion exceeded $80 \%$ in the large cohort of Swedish newborns recently collected by Karger et Albertsson-Wikland (1). In the absence of this initial catch up growth, the persistance of prepubertal short stature leads to a reduced adult height $(2,3)$. In a personal series of 47 children born with IUGR and seen before puberty for growth retardation below -2 SDS, the mean adult heights were respectively $161.9 \pm 8.0 \mathrm{~cm}$ in males and $147.6 \pm 7.2$ in females, values highly significantly lower than the target heights of these patients (4). In addition, $21 \%$ of the short stature adult population is represented by subjects born with IUGR (1). This reduction in both prepubertal and adult height, indicates the possible usefullness of GH therapy in short children borned with IUGR. The aim of the present report is to summarize the results of 3 multicenter French studies using various doses of GH during 3 years in relatively large series of short children born with IUGR. Additionally a post treatment follow up of 1 year was analyzed in 2 of these trials.

Correspondence: Dr. Jean-Louis Chaussain, Hôpital St Vincent de Paul, 74 Avenue Denfert Rochereau, F75014, Paris, France

\section{Materials and Methods}

216 prepubertal children with short stature below 2 SDS born with heights inferior to -2 SDS according to the standards established by Usher and MacLean (5) were enrolled in 3 French protocols of GH therapy. All these children had normal GH secretion on at least one pharmacological stimulation test, normal skeleton $\mathrm{X}$ rays and in girls, a normal karyotype. Patients with great prematurity ( $<35$ weeks of gestation) or documented syndromes, including Silver Russel, were excluded from these protocols. The mean characteristics of the patients included are given in Table 1.

The 3 protocols varied in the age of the enrolled children, the dose and brand of $\mathrm{GH}$.

Trial 1 included 130 children with ages ranging between 4 and 8 years. The patients were randomized between a non placebo control group and $2 \mathrm{GH}$ doses: 0.7 and $1.4 \mathrm{U} / \mathrm{kg} /$ week. $\mathrm{GH}$ used in this study was Genotonorm (Pharmacia). Data at 2 years have been previously published (6).

Trial 2 included 55 children with ages ranging between 4 and 11 years in boys, 4 and 10 years in girls. The patients were randomized between 2 doses: 0.4 and $1.2 \mathrm{U} / \mathrm{kg} /$ week. $\mathrm{GH}$ 
Table 1 Characteristics of patients included in 3 French trials

\begin{tabular}{cccccc}
\hline Trial & $\begin{array}{c}\text { Gestation } \\
\text { (weeks) }\end{array}$ & $\begin{array}{c}\text { Birth height } \\
\text { (cm) }\end{array}$ & $\begin{array}{c}\text { Birth weight } \\
\text { (g) }\end{array}$ & $\begin{array}{c}\text { Father's height } \\
\text { (cm) }\end{array}$ & $\begin{array}{c}\text { Mother's height } \\
\text { (cm) }\end{array}$ \\
\hline 1 & $39 \pm 1.8$ & $43.6 \pm 2.8$ & $2,200 \pm 500$ & $170 \pm 6$ & $157 \pm 5$ \\
2 & $39.1 \pm 1.6$ & $43.6 \pm 2.6$ & $2,145 \pm 520$ & $171 \pm 5$ & $157 \pm 6$ \\
3 & $37.8 \pm 2.9$ & $42.7 \pm 3.7$ & $2,031 \pm 551$ & $170 \pm 7$ & $157 \pm 8$ \\
\hline
\end{tabular}

Table 2 Baseline characteristics of patients included in 3 French trials

\begin{tabular}{lcccccc}
\hline & $\mathrm{N}$ & $\begin{array}{c}\text { Dose } \\
(\mathrm{U} / \mathrm{kg} / \mathrm{w})\end{array}$ & $\begin{array}{c}\text { Age } \\
\text { (years) }\end{array}$ & $\begin{array}{c}\text { Height } \\
\text { (SDS) }\end{array}$ & $\begin{array}{c}\text { Bone Age } \\
\text { (Years) }\end{array}$ & $\begin{array}{c}\text { Growth } \\
\text { velocity } \\
\text { (cm/year) }\end{array}$ \\
\hline Trial 1 & 27 & 0 & $4.3 \pm 1.4$ & $-2.8 \pm 0.5$ & $3.9 \pm 1.3$ & $5.2 \pm 0.9$ \\
(Genotonorm) & 55 & 0.7 & $5.3 \pm 1.4$ & $-3.0 \pm 0.8$ & $4.0 \pm 1.3$ & $5.1 \pm 0.5$ \\
& 48 & 1.4 & $5.7 \pm 1.3$ & $-2.9 \pm 0.8$ & $4.8 \pm 1.4$ & $4.7 \pm 0.9$ \\
\hline Trial 2 & 15 & 0.4 & $8.4 \pm 0.6$ & $\AA ̊ 2.3 .1 \pm 0.2$ & $6.9 \pm 0.7$ & $5.8 \pm 0.5$ \\
(Maxomat) & 40 & 1.2 & $8.1 \pm 0.3$ & $-3.2 \pm 0.1$ & $6.9 \pm 0.3$ & $4.8 \pm 0.6$ \\
\hline Trial 3 & 31 & 1.4 & $4.8 \pm 1.8$ & $-3.3 \pm 0.6$ & $3.5 \pm 1.7$ & $5.5 \pm 2.0$ \\
(Saizen) & & & & & & \\
\hline
\end{tabular}

used in this study was Maxomat (Sanofi). Data at 2 and 4 years have been previously published $(7,8)$.

Trial 3 concerned 31 children aged 2 to 8 years, treated with a single dose of GH: $1.4 \mathrm{U} / \mathrm{kg} /$ week. GH used in this study was Saizen (Serono).

Baseline characteristics of patients included in these 3 trials are given in Table 2 .

In the 3 trials growth hormone was administred for 3 years in daily subcutaneous injections. An additional follow up of 1 year is available in trials 1 and 2 . In trial 1 at the end of the 3rd year, patients were randomized between interruption of $\mathrm{GH}$ and continuation for an additionnal year. In trial 2, GH was interrupted in all the children.

\section{Results}

\section{Effects of the 3 years of GH therapy}

As shown on Table 3, GH therapy induced a catch up growth ranging between +0.7 and +
2.0 SDS, variable with the dose. This dose effect relationship is illustrated on Fig, 1. A spontaneous catch up growth of 0.7 SDS was observed in the control group. The rate of bone maturation was accelerated in all groups of patients, including in the control group, without any relationship with the dose (Table 3).

\section{Post treatment year}

The evolution of height in SDS during the 4th year without treatment (trials 1 and 2), or with an additionnal year of GH therapy (trial 1) is shown in Tables 4 and 5 .

\section{Puberty}

Puberty started in 34 patients of trial 2 during the 3 rd year on $\mathrm{GH}$, and in 10 others during the 4 th year (off $\mathrm{GH}$ ). The mean chronological age at the onset of puberty was 12.6 years in boys, 11.0 years in girls, with mean bone ages of 11.3 years in boys and 9.7 years in girls. 
Table 3 Results of 3 years of GH therapy in patients included in 3 French protocols

\begin{tabular}{|c|c|c|c|c|c|c|c|c|}
\hline & \multicolumn{3}{|c|}{ Baseline } & \multicolumn{3}{|c|}{3 years } & \multirow[b]{2}{*}{$\begin{array}{l}\Delta \text { height } \\
\text { (SDS) }\end{array}$} & \multirow[b]{2}{*}{$\begin{array}{c}\Delta \mathrm{BA} \\
\text { (years) }\end{array}$} \\
\hline & $\begin{array}{c}\mathrm{CA} \\
\text { (years) }\end{array}$ & $\begin{array}{l}\text { Height } \\
\text { (SDS) }\end{array}$ & $\begin{array}{c}\text { BA } \\
\text { (years) }\end{array}$ & $\begin{array}{c}\text { CA } \\
\text { (years) }\end{array}$ & $\begin{array}{l}\text { Height } \\
\text { (SDS) }\end{array}$ & $\begin{array}{c}\text { BA } \\
\text { (years) }\end{array}$ & & \\
\hline \multicolumn{9}{|l|}{ Trial 1} \\
\hline Control & $4.3 \pm 1.4$ & $-2.8 \pm 0.5$ & $3.9 \pm 1.3$ & $7.3 \pm 1.4$ & $-2.1 \pm 0.3$ & $7.8 \pm 0.7$ & $+0.7 \pm 0.5$ & $3.9 \pm 0.7$ \\
\hline $0.7 \mathrm{U} / \mathrm{kg} / \mathrm{w}$ & $5.3 \pm 1.4$ & $-3.3 \pm 0.6$ & $4.0 \pm 1.3$ & $8.3 \pm 1.4$ & $-1.9 \pm 0.9$ & $8.0 \pm 1.0$ & $+1.2 \pm 0.4$ & $4.0 \pm 1.2$ \\
\hline $1.4 \mathrm{U} / \mathrm{kg} / \mathrm{w}$ & $5.7 \pm 1.7$ & $-2.9 \pm 0.8$ & $4.8 \pm 1.4$ & $8.7 \pm 1.7$ & $-1.6 \pm 0.8$ & $9.0 \pm 1.1$ & $+1.5 \pm 0.4$ & $4.2 \pm 1.0$ \\
\hline \multicolumn{9}{|l|}{ Trial 2} \\
\hline $0.4 \mathrm{U} / \mathrm{kg} / \mathrm{w}$ & $8.4 \pm 0.6$ & $-3.1 \pm 0.1$ & $6.9 \pm 0.7$ & $11.4 \pm 0.6$ & $-2.4 \pm 0.3$ & $10.3 \pm 1.2$ & $+0.7 \pm 0.3$ & $3.4 \pm 0.8$ \\
\hline $1.2 \mathrm{U} / \mathrm{kg} / \mathrm{w}$ & $8.1 \pm 0.3$ & $-3.2 \pm 0.2$ & $6.0 \pm 1.3$ & $11.1 \pm 0.3$ & $-1.6 \pm 0.1$ & $9.8 \pm 0.7$ & $+1.6 \pm 0.1$ & $3.8 \pm 0.6$ \\
\hline \multicolumn{9}{|l|}{ Trial 3} \\
\hline $1.4 \mathrm{U} / \mathrm{kg} / \mathrm{w}$ & $4.8 \pm 1.8$ & $-3.3 \pm 0.6$ & $3.5 \pm 1.7$ & $7.8 \pm 1.8$ & $-1.3 \pm 0.9$ & $7.3 \pm 2.0$ & $+2.0 \pm 0.8$ & $3.8 \pm 1.9$ \\
\hline
\end{tabular}

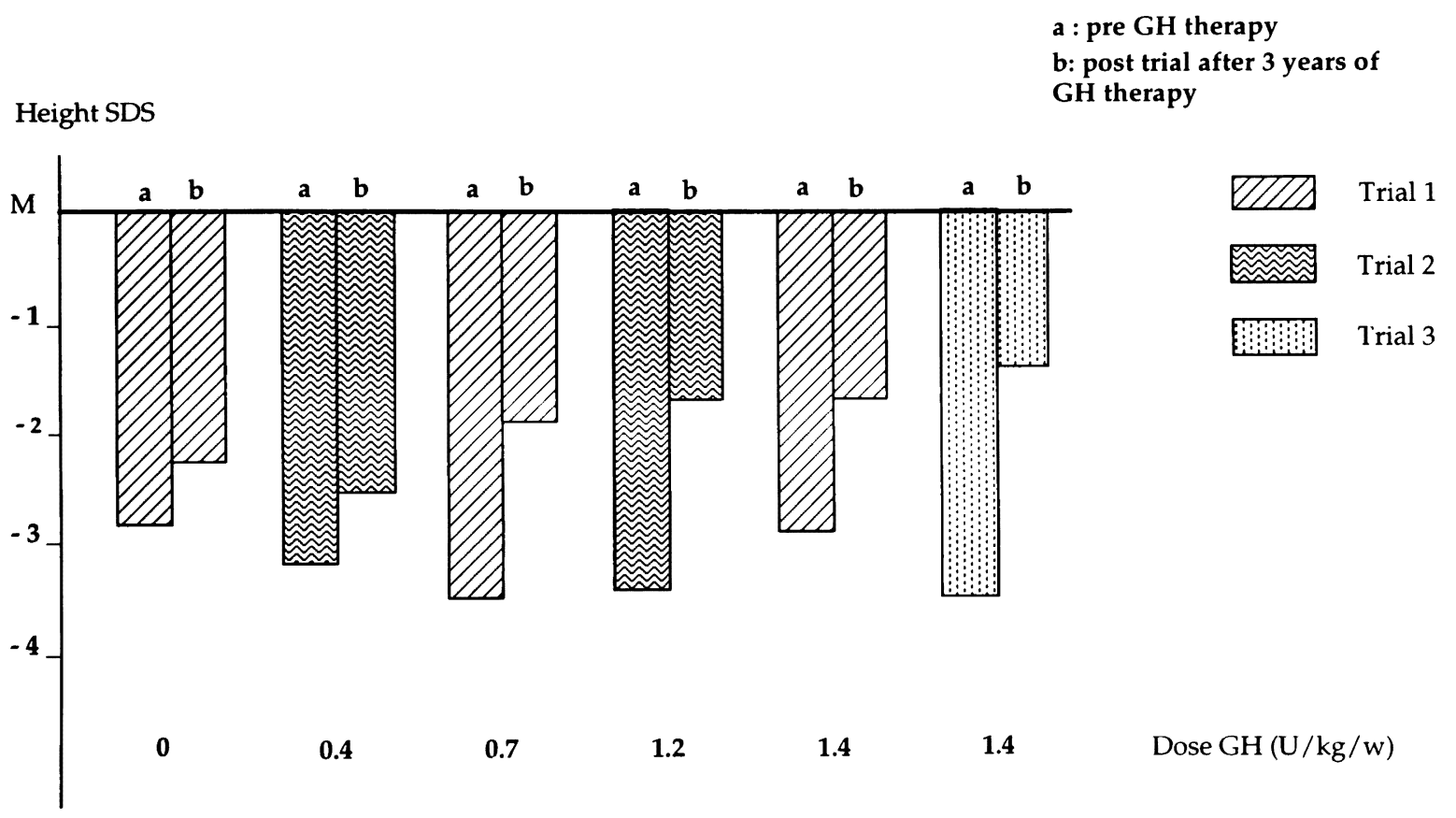

Fig. 1 Dose effect relationship.

\section{Discussion}

In the 3 French trials reported in this review, 3 years of GH therapy induced a catch up growth in prepubertal short children born with IUGR. The amplitude of the height gain at the end of the third year is clearly related to the dose of $\mathrm{GH}$ administrated. With a relatively low dose of $0.4 \mathrm{U} / \mathrm{kg} /$ week the gain of $+0.7 \mathrm{SDS}$ is absolutely identical to the spontaneous gain observed in the control group of trial 1. In this range of doses the use of GH appears as highly questionable. In contrast, when $\mathrm{GH}$ is given at 
Table 4 Evolution of height during the year following GH cessation

\begin{tabular}{lccc}
\hline & $\begin{array}{c}\text { Height at 3 years } \\
\text { (SDS) }\end{array}$ & $\begin{array}{c}\text { Height at 4 years } \\
\text { (SDS) }\end{array}$ & $\begin{array}{c}\Delta \text { height } \\
\text { (SDS) }\end{array}$ \\
\hline Trial 1 & & & \\
$0.7 \mathrm{U} / \mathrm{kg} / \mathrm{w}$ & $-1.4 \pm 0.8$ & $-1.9 \pm 0.8$ & $-0.5 \pm 0.6$ \\
$1.4 \mathrm{U} / \mathrm{kg} / \mathrm{w}$ & $-0.9 \pm 0.7$ & $-1.0 \pm 0.4$ & $-0.1 \pm 0.2$ \\
\hline Trial 2 & & & \\
$0.4 \mathrm{U} / \mathrm{kg} / \mathrm{w}$ & $-2.2 \pm 0.3$ & $-2.5 \pm 0.4$ & $-0.3 \pm 0.2$ \\
$1.2 \mathrm{U} / \mathrm{kg} / \mathrm{w}$ & $-1.6 \pm 0.1$ & $-1.8 \pm 0.2$ & $-0.2 \pm 0.1$ \\
\hline
\end{tabular}

Table 5 Evolution of height in patients treated for 4 years $(\mathrm{N}=42)$

\begin{tabular}{lccc}
\hline & $\begin{array}{c}\text { Height after } \\
\text { 3 years } \\
\text { (SDS) }\end{array}$ & $\begin{array}{c}\text { Height at } 4 \text { years } \\
\text { (SDS) }\end{array}$ & $\begin{array}{c}\Delta \text { height } \\
\text { (SDS) }\end{array}$ \\
\hline Trial 1 & & & \\
$0.7 \mathrm{U} / \mathrm{kg} / \mathrm{w}$ & $-2.0 \pm 1.2$ & $-1.8 \pm 0.5$ & $+0.2 \pm 0.6$ \\
$1.4 \mathrm{U} / \mathrm{kg} / \mathrm{w}$ & $-1.8 \pm 0.5$ & $-1.5 \pm 0.6$ & $+0.3 \pm 0.4$ \\
\hline
\end{tabular}

doses ranging between 1.2 and $1.4 \mathrm{U} / \mathrm{kg} /$ week, the gain obtained in the 3 different trials analyzed here, varied between +1.5 and +2.0 SDS. As the initial mean growth deficit of the subjects enrolled in these trials was around - 3 SDS, the 3 years protocols were sufficient to normalize the height of the patients, or at least to move them to the lower half of the normal distribution of height. Moreover, the interpretation of these results must take into account the fact that mean parental heights were low in the 3 trials indicating reduced target heights in these children. Therefore it seems reasonable to conclude that the 3 years of GH therapy have induced a major benefit in this range of doses. The use of doses higher than those used in these 3 studies has also been proposed (9).

An increased rate of epiphysial maturation was observed in all the treated patients, without any reference with the dose. This acceleration of bone age, 3.84 years in mean during the 3 years of therapy, leads to a reduction of the expected benefit in terms of final height prognosis.
The improvement of adult height when low doses of $\mathrm{GH}$ are used is certainly questionable, as observed in the patients reported by Stanhope et al. (10). However the increased rate of bone maturation was also observed in the control group of trial 1, and the role of GH therapy in this process is not evident. Nevertheless, the amplitude of the catch up growth induced by doses superior to $1 \mathrm{U} / \mathrm{kg} /$ week is sufficient to lead to a very significant improvement of final height prognosis, despite of the acceleration of bone maturation.

The interruption of $\mathrm{GH}$ is followed by a deceleration of growth velocity, with a loss of part of the benefit. This loss appears as extremely small, ranging between 0.1 and 0.5 SDS. In the 2 groups treated with doses over $1 \mathrm{U} / \mathrm{kg} /$ week the loss was respectively 0.1 and 0.2 SDS. The continuation of GH therapy for a fourth year leads to a stabilisation of the benefit with a limited increase in height of 0.2 to 0.3 SDS according to the dose. This limited effect does not justify a prolongation of therapy after 3 years, in respect 
to the economic cost of such a prolongation and to the potential risk of prolonged administration of $\mathrm{GH}$ in non deficient children, even if no side effects were observed in our studies.

In these conditions it seems reasonable to expect that 3 years of GH therapy will improve the final height of these patients. However an influence of GH therapy on the timing and amplitude of the pubertal growth spurt cannot be excluded at the present time. In comparison with historical series (4), patients of trial 2 entered into puberty one year earlier in terms of chronological age, but with exactly the same level of bone maturation.

As the height at the onset of puberty is strongly correlated with the adult height in patients with short stature secondary to IUGR (4) this fact leads also allows us to predict a probable improvement of final heights in our patients.

\section{References}

1. Karlberg J, Albertsson-Wikland K. Growth in fullterm small-for-gestational-age infants: From birth to final height. Pediatr Res 1995; 38: 733-9.

2. Paz I, Seidman DS, Danon YL, Laor A, Stevenson DK, Gale R. Are children born small for gestational age at increased risk of short stature? Am J Dis Child 1993; 147: 337-9.

3. Albertsson-Wikland K, Karlberg J. Natural growth in children born small for gestational age with and without catch-up growth. Acta Paediatr Suppl 1994; 399: 64-70.

4. Chaussain JL, Colle M, Ducret JP. Adult height in children with prepubertal short stature secondary to intrauterine growth retardation. Acta Paediatr Suppl 1994; 399: 72-3.

5. Usher R, McLean F. Intrauterine growth of liveborn caucasian infants at sea level: standards obtained from measurements in 7 dimensions of infants born between 25 and 44 weeks of gestation. J Pediatr 1969; 74: 901-10.

6. Chaussain JL, Colle M, Landier F. Effects of growth hormone therapy in prepubertal children with short stature secondary to intrauterine growth retardation. Acta Paediatr 1994; 399: 745.

7. Chatelain P, Job JC, Blanchard J, Ducret JP, Olivier M, Sagnard L, et al. Dose-dependent catch-up growth after 2 years of growth hormone treatment in intrauterine growth-retarded children. J Endocr Meta 1994; 78: 1454-60.

8. Job JC, Chaussain JL, Job B, Ducret JP, Maes M, Olivier M, et al. Pediatr Res 1996; 39: 354-9.

9. Zegher F, Maes M, Gargosky SE, Heinrichs C, Caju MVL, Thiry G, et al. High-dose growth hormone treatment of short children born small for gestational age. J Clin Endocr Meta 1996; 81: 1887-92.

10. Stanhope R, Preece MA, Hamill G. Does growth hormone treatment improve final height attainment of children with intrauterine growth retardation? Arch Dis Child 1991; 66: 1180-3. 